\title{
Patient-reported benefits from patient organization magazines and Internet-based peer support in Ménière's disease
}

This article was published in the following Dove Press journal:

Patient Preference and Adherence

26 October 2017

Number of times this article has been viewed

\author{
Vinaya Manchaiah ${ }^{1-4}$ \\ Ilmari Pyykkö 5 \\ Jing Zou ${ }^{5,6}$ \\ Hilla Levo ${ }^{7}$ \\ Erna Kentala ${ }^{7}$ \\ 'Department of Speech and \\ Hearing Sciences, Lamar University, \\ Beaumont, TX, USA; ${ }^{2}$ Department of \\ Behavioural Sciences and Learning, \\ The Swedish Institute for Disability \\ Research, Linköping University, \\ Linköping, Sweden; ${ }^{3}$ Audiology India, \\ Mysore, ${ }^{4}$ Department of Speech and \\ Hearing, School of Allied Health \\ Sciences, Manipal University, Manipal, \\ Karnataka, India; ${ }^{5}$ Department \\ of Otolaryngology, Hearing and \\ Balance Research Unit, University \\ of Tampere, Tampere, Finland; \\ ${ }^{6}$ Department of Otolaryngology- \\ Head and Neck Surgery, Center for \\ Otolaryngology-Head \& Neck Surgery \\ of Chinese PLA, Changhai Hospital, \\ Second Military Medical University, \\ Shanghai, China; ${ }^{7}$ Department of \\ Otolaryngology, University of Helsinki, \\ Helsinki, Finland
}

Objectives: To facilitate self-help, the Finnish Ménière's Federation (FMF) provides various kinds of support to persons with Ménière's disease (MD), which includes patient magazines (PM) and Internet-based peer support (iPS). The current study aimed to evaluate the benefits reported by MD patients in terms of PM and iPS.

Method: The study used a cross-sectional survey design with a mixture of structured and open-ended questions administered online. A sample of 185 patients from the FMF membership database provided complete data.

Results: Ninety-two percent of the respondents rated PM as useful, or very useful. The main benefits of PM included: information on the disease and complaints, information about elements of peer support program, patient's experience with useful positive case studies, relevant news on MD, and information of activity of the FMF. Of the 185 persons, 68 reported that they did not have a need for peer support as their disease was either in silent phase or did not cause any annoyance. The main reasons for nonuse were: mild disease, personal reasons, and problems in using. Regarding the benefits of iPS, 75\% of recent and $64 \%$ of chronic MD patients said that they would benefit from such a program. The main benefits of iPS included: reliable information on the disease and its management, peer support useful for coping with the disease, information about managing MD symptoms, information about managing attitude, and information about therapy. Moreover, the study identified different groups of individuals, which included: nonusers of support from patient organizations, those who used the support but did not feel they benefited, and those who used and also benefited from such programs.

Conclusion: The current study results provide some information about the preferences of MD patients regarding different forms of support and could certainly prove helpful while developing wider support strategies.

Keywords: Ménière's disease, chronic condition, peer support, self-help, self-management

\section{Introduction}

Ménière's disease (MD) is a condition of the inner ear manifested in episodic vertigo, hearing loss, fullness of the ear, and tinnitus. MD is a chronic illness affecting about 513 per 100,000 persons. $^{1}$ The majority of persons with MD are over 40 years of age, and MD is more prevalent among females than males. The attacks of MD may occur in clusters in which several attacks may occur within a short period; on the other hand, years may pass between episodes making this disease very unpredictable. MD originates in the inner ear, although the etiology of the disorder is unknown. The condition has a chronic but often unpredictable course, leading to functional limitations
Correspondence: Vinaya Manchaiah Department of Speech and Hearing Sciences, Lamar University, PO Box 10076, Beaumont 77010, TX, USA

$\mathrm{Tel}+\mathrm{I} 4098808927$

Fax +I 4098802265

Email vinaya.manchaiah@lamar.edu 
and restrictions, and is not fully restored by medical therapy alone. MD also challenges the health care system. ${ }^{2}$ Data from the UK estimated the cost of MD equating about $€ 3,200$ per person per annum, adding up to $€ 520$ million as annual cost for health care in the UK alone. The indirect costs are substantial, with loss of earnings contributing to over $€ 360$ million per annum. ${ }^{2}$

MD has many adverse consequences on health (eg, hearing difficulty, balance problems), and on psychological welfare (increased anxiety and depression, fatigue, social isolation) that affect both individuals and their family members. ${ }^{3}$ The MD causes poorer health-related quality of life (HRQoL) and ultimately results in societal problems. Successful management of chronic conditions requires the individual to have an understanding of their circumstances in order to make decisions regarding treatment, to be able to perform activities that help manage the condition, and to apply abilities that maintain psychosocial functioning. ${ }^{4}$ Various patient organizations have become aware of the health problems and life consequences associated with MD and have consequently established supportive programs such as informational and educational sessions and peer support programs (for review, see Heisler ${ }^{5}$ ). These programs are focused on promoting self-management in which patient involvement, leadership, and ownership of care are prioritized in order to improve coping with the condition. One such approach is the use of peer support, which is an intervention that leverages shared experience in order to foster trust, decrease stigma, and create a sustainable forum for seeking help and sharing information. ${ }^{6}$

In conventional peer support, the patient and practitioner meet face-to-face to discuss the various aspects of the disease and its management. ${ }^{7}$ It is recommended that these meetings take place frequently and include an action plan with specific self-care tasks..$^{5}$ Alternatively, some therapists and organizations use a booklet-based self-management approach to facilitate self-help in people with various chronic conditions. Such approaches have shown to be an inexpensive and effortless way to help people deal with their symptoms in MD and were found to be beneficial when compared with a control group without booklets. ${ }^{8,9}$

In recent years, social media and Internet-based selfhelp and peer support programs have become popular in the management of chronic conditions. ${ }^{8}$ Such examples of Internet-based self-help and guided therapies are also shown to be effective in the management of hearing loss, tinnitus, and balance disorders. ${ }^{10-14}$ The self-help programs often have demanding recommendations (eg, medication regimen, instructions to change attitude and expectations, careful self-monitoring, and diet and exercise programs). Hence, the success of many of these self-help programs for chronic disease depends largely on the willpower and ability of persons to follow the instructions. To complicate matters further, many persons face additional challenges such as multiple comorbidities, physical limitation, and poor support from family and society. ${ }^{5}$ However, with the modern information technology and electronic social networks, patient organizations have developed new opportunities to provide personal, group-based and individual Internet-based selfhelp programs. These novel self-help and self-management programs are far less expensive when compared to traditional clinical help and support offered by the medical and rehabilitation professionals. We believe that a healthy approach would be to use such programs as supplementary to disease management in order to improve health outcomes and reduce the social burden of chronic conditions such as MD. However, not much research currently exists for voluntary patient organizations to develop a methodology for determining what blend of real/virtual hybrid products, services, and processes complement their core business and strategic trajectory.

The Finnish Ménière's Federation (FMF) provides various types of assistance to facilitate self-help and self-management for its members. These include: 1) quarterly patient magazines (PM) Ménière-Post and 2) Internet-based peer support (iPS) program. The quarterly PM is provided four times a year and contains information about various kinds of therapy, disease description, tips for adapting and coping with the condition, positive case studies, and doctors reply to specific questions asked by persons with MD. The iPS program includes computer-based disease assessment, an online selfhelp program to facilitate coping, and comparison of patients' condition and progress with similar referent cases. ${ }^{12-14}$ These two types of assistance are aimed to provide information, change the attitude, and improve to cope well with the condition. The information is supplementary to the routine medical care and aims to promote self-management of MD among the affected individuals and their significant others.

The current study aimed to evaluate the benefits reported by the FMF members (ie, MD patients) about PM and iPS.

\section{Method \\ Study design}

The study used a cross-sectional survey design. The FMF contacted their members, asking them to complete an extensive questionnaire on their symptoms related to MD. As the data presented in this study were gathered by a 
patient-led organization, the data become part of the public register. Hence, the current study did not require ethical approval according to the Medical Research Act, Finland (Law 488/1999). ${ }^{15}$ The questionnaire was administered using Doodle (www.doodle.com), which is an online platform used to create surveys and poll-based tools. Completing and returning the questionnaire was considered as consent.

\section{Participants}

A convenience sample of 226 subjects (ie, those having Internet access) was drawn from the FMF membership database (952 members) and they were invited to participate in the survey, of which a total of 185 replied (ie, response rate of $82 \%$ ). The mean age of participants was $55 \pm 5$ years. From the participating subjects, 136 (ie, $73.5 \%$ ) were females and 49 (ie, 26.5\%) were males, reflecting the gender distribution of FMF.

\section{Data collection}

The 12-item questionnaire was used for assessing the usefulness of different types (ie, magazines from patient organizations and iPS) of support provided by the FMF. In the survey, there were 6 structured questions on the usefulness of various forms of support and their outcomes and 7 open-ended questions in that the persons could verbally comment on the structured questions and provide reasoning for their replies (Table 1). The usefulness and applicability was rated with a 5-point scale from "no benefit" to "significant benefit." For each of these structured questions, there were 1 or 2 boxes for open comments asking to report why and/or how.

All the participants were asked question about how the PM and iPS were applicable for both recent (ie, onset of the disease for less than 1 year) and chronic (ie, onset of the disease for at least 1 year or longer) MD patients. The FMF members have an average duration of MD as 16.5 years (SD: 12 years) with over $95 \%$ of people having had MD for

Table I Structured questions used in the survey

How useful do you consider Ménière patient magazines (appearing four times in a year) from Finnish Ménière's Federation? How much help could a recently disabled (less than I year) Ménière disease person obtain from an Internet-based peer-support program? How much help could a chronically disabled (I year or more) Ménière disease person obtain from an Internet-based peer-support program? After peer support, do you understand your Ménière disease in a different way or in a new light?

Could a peer support program support your collaboration with your doctor in a therapeutic aspect?

If some other disease would disable you, would you like to have a program similar to the peer support for Ménière disease? longer than 1 year. Hence, we felt it was appropriate to ask them about how the support materials were appropriate for both recent and long-standing MD patients.

\section{Data analysis}

Responses to open-ended questions were analyzed using the qualitative content analysis. ${ }^{16}$ The open questions were analyzed by two authors (IP and VM) and scaled based on International Classification of Functioning, Disability, and Health (ICF) into different categories, when appropriate. Thereafter, a consensus was made and the data were used for statistical analysis and presentation.

Descriptive statistics were explored on the data from structured questionnaires. A nonparametric Wilcoxon signedrank test was used to explore the relationship between the demographic variables and the participants' responses. This was followed by the use of a " $K$-means cluster analyses (ie, nearest neighbour analysis)" to profile the responses of participants. The $K$-means quick cluster algorithm offers a cluster analysis of the variables and aims to identify relatively homogenous groups of cases and/or variables based on selected characteristics. A $p$-value of 0.05 was used for statistical significance interpretation.

\section{Results}

\section{Benefits from patient-focused magazines}

From the 185 replies, $96 \%$ of the people found the content of the PM useful (Table 2). When exploring the benefits the patient received from the PM using open-ended questions, 131 respondents gave 222 replies on the content of the PM and how it influenced their well-being (Figure 1). The most frequently occurring responses about the benefits of PM included: information on the disease and complaints $(n=89)$, information about elements of peer support program $(n=42)$, patient's experience with useful positive case studies $(n=25)$, and relevant news on MD $(n=23)$.

\section{Benefits from the iPS program}

We asked about the usefulness of the iPS for chronic MD patients, and of the 185 respondents, 117 said they had used the iPS and the remaining 68 said they did not complete the iPS although they had started it. We interpret this to mean that those with a long history of MD know how to manage the disease sufficiently well, and they were not willing to change their attitude toward the illness.

We asked the users' opinion on the usefulness of iPS for those with less than 1 year since diagnosis (acute MD) and for those with a disease history longer than 1 year (chronic MD). 
Table 2 Usefulness and applicability of the patient magazine (PM) and virtual Internet-based peer support (iPS) program

\begin{tabular}{llllll}
\hline Questions & Do not know (\%) & No (\%) & Moderately (\%) & Much (\%) & Very much (\%) \\
\hline How useful do you consider the PM appearing four times in a year? & 3 & 1 & 7 & 38 & 49 \\
How much help did you get from the iPS (recent MD)? & 24 & 1 & 7 & 32 & 36 \\
How much help did you get from the iPS (chronic MD)? & 32 & 2 & 15 & 29 & 22 \\
Do you understand your MD better having followed the iPS? & 37 & 2 & 16 & 27 & 19 \\
\hline
\end{tabular}

Abbreviation: MD, Ménière's disease.

For acute MD, $68 \%$ of the persons regarded the iPS as useful or very useful, whereas only 1 person regarded it as not useful at all (Table 2).

When answering the question about the benefits of iPS for acute MD patients, of the 185 subjects, only 93 respondents provided answers to open-ended questions. They provided 159 replies for acute disease and 99 replies for chronic disease (Figure 2). The most important benefits for acute MD included: reliable information on the disease and its management $(n=64)$, peer support they received that was useful to enhance coping with the disease $(\mathrm{n}=29)$, information about managing the MD symptoms $(\mathrm{n}=24)$, information about managing the attitude $(\mathrm{n}=10)$, and information about therapy $(\mathrm{n}=10)$.

From the 185 persons, $51 \%$ regarded that the iPS would be useful or very useful in chronic MD (Table 2). Two persons replied that they did not see or experience any benefit from the program and preferred personal peer support $(\mathrm{n}=1)$, or taking a 3-day course on coping skills for living with MD $(n=1)$. For open-ended questions, only 66 out of 185 respondents replied and provided 99 responses in total (Figure 2). Most of the persons experienced information on the multifaceted clinical picture of MD to be of utmost importance $(n=27)$. It was followed by peer support provided by the program $(n=19)$. The iPS program helped a large group of persons to cope with the disease and limitations brought by the disease. Seventeen persons reported managing to live well with the disease. New therapeutic possibilities were also of interest in some of the persons $(n=9)$. Other items were support provided by the patient organization, comparison with others, learning from other persons, and change of one's own attitude. For 11 persons, the iPS was not of any use.

Using the nonparametric Wilcoxon signed-rank test, we compared the possible differences in terms of respondents' opinions about the benefits of iPS for recent and chronic MD patients. The results suggest that the respondents felt that patients with recent MD would benefit significantly more from the iPS $(p<0.001)$.

We also asked whether after passing iPS if they understand MD in a different way. From those answering the question, 85 of 185 persons considered changes in their understanding of MD as much or very much (Table 2).

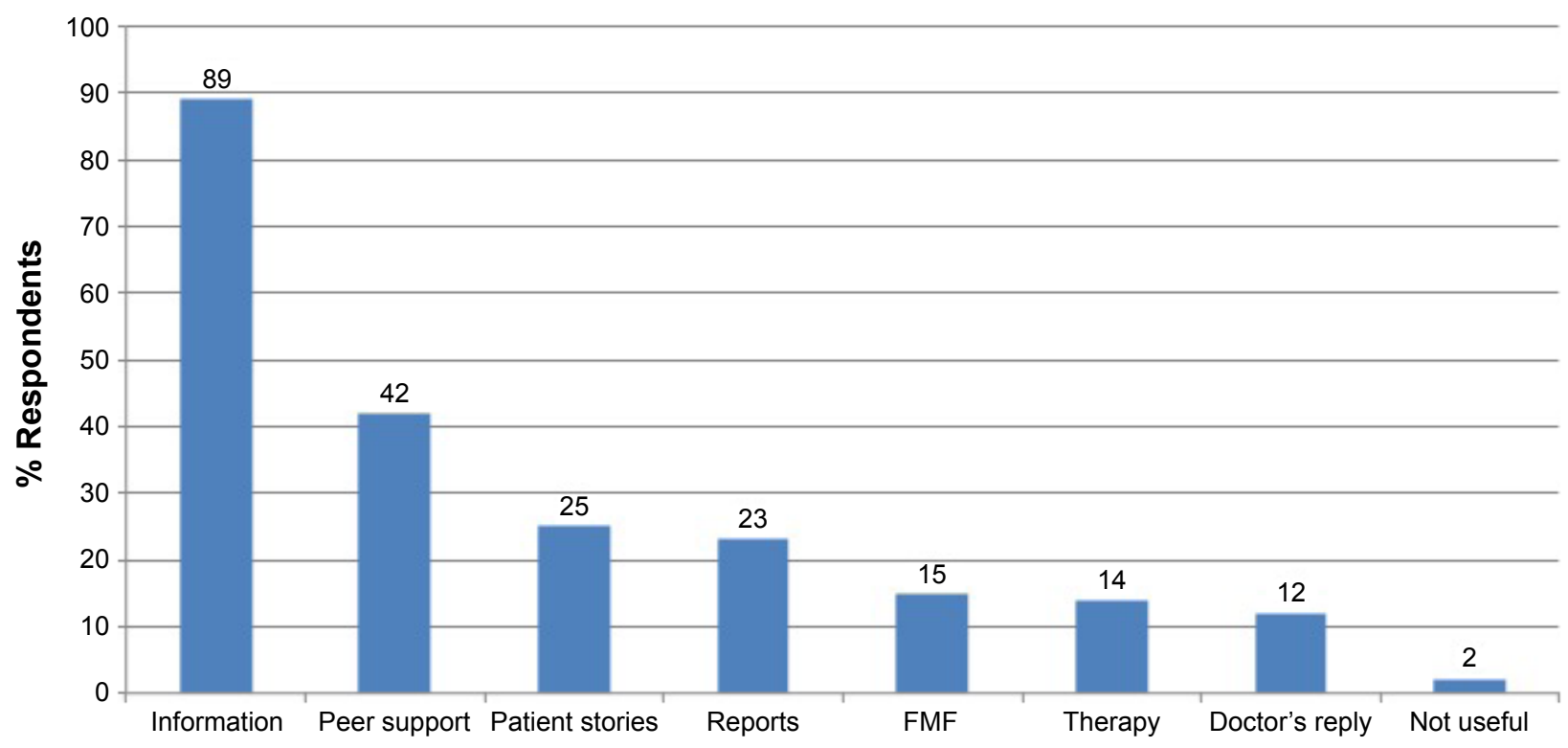

Figure I Usefulness of the content found in patient magazines.

Note: The graph is based on 222 replies from 131 respondents to an open-ended question.

Abbreviation: FMF, Finnish Ménière's Federation. 


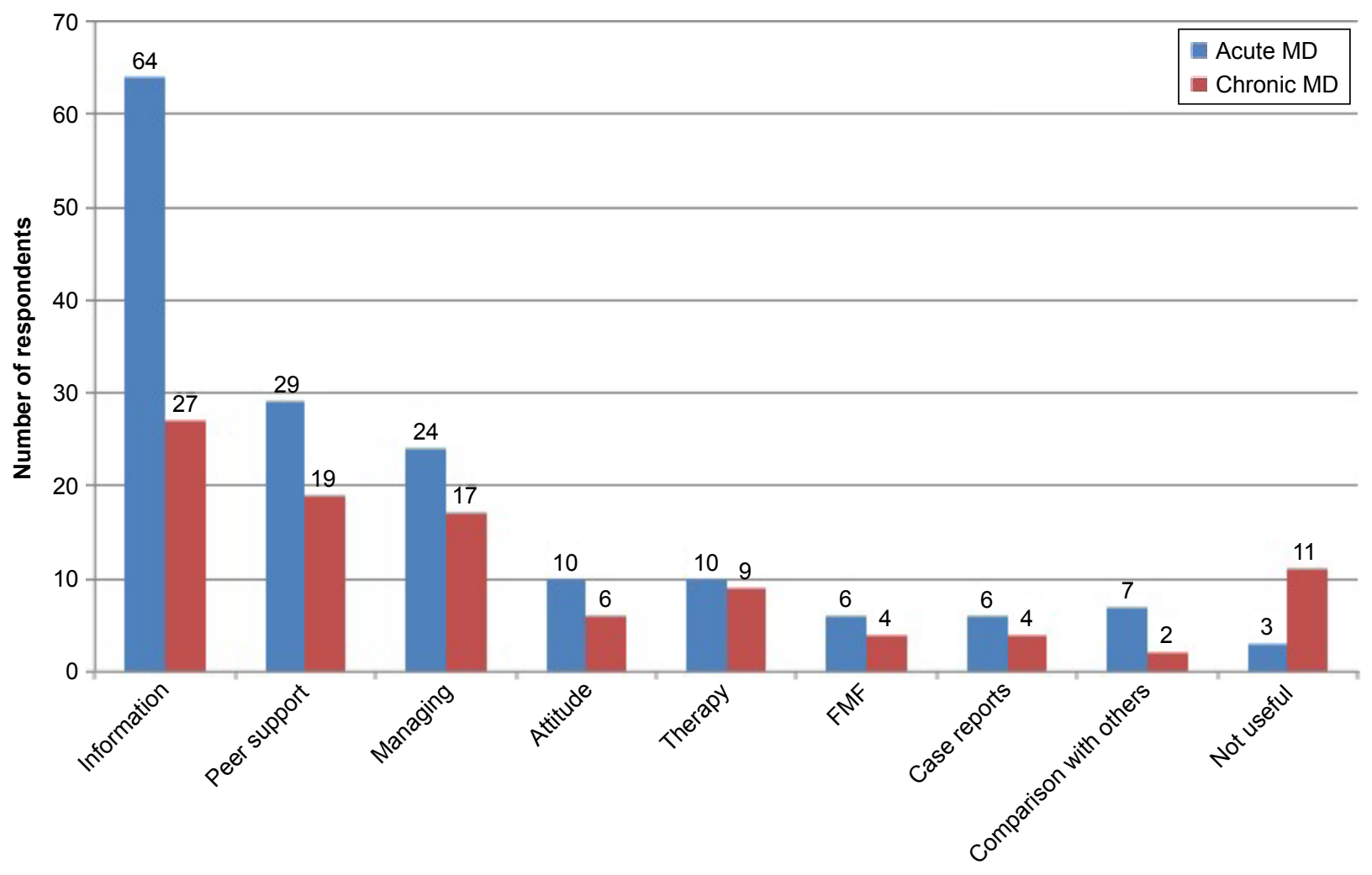

Figure 2 Usefulness of the content of the Internet-based peer support program on acute and chronic Ménière's disease patients.

Note: The graph is based on 159 replies for acute disease and 99 replies for chronic disease from 93 respondents to an open-ended question.

Abbreviations: FMF, Finnish Ménière's Federation; MD, Ménière's disease.

Sixty-eight people did not work with the program or finish the program and therefore could not reply on possible changes. However, 29 persons considered that iPS changed their attitude only moderately, and 3 persons reported that they experienced no change. Items that changed after passing the iPS were most commonly based on better management of their problems $(n=45)$ and on receiving more information about MD ( $\mathrm{n}=13)$.

Concerning the usability of the iPS, of the 31 respondents, 15 said the program was easy to use while 16 replied that they had problems using the program. The main reasons for difficulty using the program included: program too long and complicated $(n=11)$; data failure problem in usage $(n=2)$; personal reasons $(n=2)$; and felt the program unnecessary and/or not useful $(n=1)$.

The participants were asked to indicate the reason for not using the iPS, and 51 responses were received. The main reason for not using the program was that the persons claimed that their disease has stopped and/or was not bothering them, and henceforth felt that there would be no benefit in using the program $(n=20)$. The second most $(n=17)$ common were the personal reasons (eg, no time, being lazy, etc.). The other reasons included: insufficient information on iPS $(n=7)$; program was too complex $(n=2)$; other disease interfered $(n=1)$; and two had problems using it (eg, forgotten password, broken computer, tablet problem).

\section{Distribution of MD patients based on their preferences of the support provided by the FMF}

We performed $K$-means cluster analysis on the participants' responses to preference and benefits of the different kinds of support provided by the FMF. This analysis helped us understand the support preferences of the groups. The analysis resulted in three clusters. The respondents in "cluster 1" $(n=42)$ suggested they used different kinds of support programs offered by the FMF, although they reported to have limited benefits from these programs. However, they reported to possess significant knowledge about their disease and appeared to appreciate the PM. The respondents in "cluster 2" $(n=57)$ were basically the nonusers, as they did not engage or use any of the support provided by the FMF. The "cluster 3" $(n=86)$ included people who appreciated the benefit of the program, both in acute and chronic stages of the disease. They also understood their complaints better and recommended a similar program for other diseases. The age of participants did not significantly change the cluster categories. However, respondents in "cluster 3 " preferred the use and content 
of the PM more as compared to the respondents in other clusters $(p=0.002)$.

\section{Discussion}

In 2002, the World Health Organization argued that improving persons' self-management in chronic disease would have far greater impact on the health of populations than any improvement by medical treatments. ${ }^{17}$ Different types of self-help and peer support programs have been launched since then, which include: booklet-based self-help, telephone calls, web-based telehealth programs, and person-to-person peer support programs. ${ }^{18}$ A combination of these programs (ie, PM, assisted telecommunications, and iPS) can be adapted for areas where limited access to services as advocated by the FMF for promoting self-management in MD. A core element of these programs is the provision of social support, skill development to cope with illness interference, improved management of daily activities, and health condition management. How this information is presented and adopted is important in promoting their relevance, acceptability, and usability to participants. Strategies to mitigate perceived stigma associated with having a chronic illness also need to be considered, as do strategies for promoting participant involvement in affecting attitude changes. The outcome varies between different support efforts, but improvements in quality of life, social attendance, and daily coping have been reported. ${ }^{14,18-20}$ However, most of these programs were laborious for users and required intentional efforts to make them easily accessible.

\section{Patient-reported benefits from different types of support}

The current program is constructed and based on the principles of traditional peer support - meaning that the problems, limitations, and restrictions are coming from the patients themselves; furthermore, the solutions are also patient originated. The current study results suggest that a large percentage of study sample felt that they benefited from PM ( 94\%) and also from iPS ( 98\%). However, the cluster analysis indicates some of these individuals had limited benefits (ie, cluster 1). Nevertheless, the benefits were mainly related to aspects such as self-oriented information about the disease and its management, information about peer support programs, positive case studies, and also reply from the doctors regarding specific questions.

The current study results suggest that there is a need for different kinds of support methods, and these should be supplementary to each other (eg, PM and iPS). In the face of challenges with regard to costs and the availability of professionals, the new iPS program, with possible assistance of social media, is especially promising for MD. ${ }^{14}$ However, it appears that many people with chronic MD did not complete the iPS program, as they felt they did not need the program. This may be related to the disease not being very severe and/or the people with long-standing conditions having already learned coping strategies successfully and thus may not see the advantage of such programs. Moreover, some elements of difficulty using the iPS programs were also discovered (eg, too long and complicated, complex program). Moreover, the study identified different groups of individuals, which included: nonusers of support from patient organizations, those who used the support but did not feel they benefited, and also those who used and also benefited from such programs. It is important for health care providers and also patient organizations to understand this, as they can henceforth develop strategies to improve accessibility and acceptability of such programs.

\section{Study limitations}

Our study sample comes from patient organization, and we also used a convenience sample and included only those who had e-mail access and who were familiar with the Internet. Thus, the results apply specifically to such populations and may not be representative of a broader MD population. Some researchers have argued that Internet-based samples may actually be more representative than traditional samples, ${ }^{21}$ although this can be questionable in the context of MD patients within the FMF membership. The MD affects men and women equally, although in the current sample $73.5 \%$ were women. This may suggest that compared to men, women are more likely to join patient organizations and possibly also participate in survey questionnaires. ${ }^{22}$ Hence, the study sample may not be representative of the general MD population. Also, when comparing Internet-based data collection with paper-and-pencil versions, Internet data appear to be reliable and need to be answered similarly to the way they are answered when they are administered via traditionally mailed paper questionnaires. ${ }^{23}$ Moreover, all participants were asked to respond about the benefits of iPS for both recent and chronic MD patients. Although, most participants may have long-standing MD and may have gone through early stages of adapting to MD, they may not remember all of their experiences, and their answers in this survey have to be read with caution.

\section{Conclusion}

The medical management of MD is not sufficient to achieve optimal outcome, and therefore supplementary support may 
be needed. However, the forms of support can be different and sometimes may overlap. The current study evaluated the benefits reported by MD patients in terms of PM and iPS. PM containing positive case reports, doctor's replies, and relevant information on the disease was considered useful and provided self-guided support and coping possibilities. iPS was used by $63 \%$ of the users $(n=117)$, of whom $98 \%$ reported that the program provided was beneficial. Moreover, the study identified different groups of individuals, which included: nonusers of support from patient organizations, those who used the support but did not feel they benefited, and also those who used and benefited from such programs. These study findings can certainly prove helpful while developing support strategies for patients with MD.

\section{Acknowledgments}

Authors acknowledge the support from the FMF for help with data collecting for this study.

\section{Disclosure}

The authors report no conflicts of interest in this work.

\section{References}

1. Havia M, Kentala E, Pyykko I. Prevalence of Meniere's disease in the general population of Southern Finland. Otolaryngol Head Neck Surg. 2005;133(5):762-768.

2. Tyrrell J, Whinney DJ, Taylor T. The cost of Ménière's disease: a novel multisource approach. Ear Hear. 2016;37(3):e202-e209.

3. Levo H, Stephens D, Kentala E, Poe D, Rasku J, Pyykkö I. EuroQol 5D quality of life in Menière's disorder can be explained with symptoms and disabilities. Int J Rehabil Res. 2012;35(3):197-202.

4. Clark N, Becker M, Janz N, Lorig K, Bakowski W, Anderson L. Selfmanagement of chronic disease by older adults: a review and questions for research. J Aging Health. 1991;3:3-27.

5. Heisler M. Building Peer Support Programs to Manage Chronic Disease: Seven Models for Success. Oakland (CA): Californian Health Care Foundation; 2006.

6. Long AF, Bennet T. Coping with Meniere's disease: experience and benefits from the use of complementary and alternative medicine. Chronic Illn. 2009;5:219-232.

7. Harrop VM. Virtual Healthcare Delivery: Defined, Modelled, and Predictive Barriers to Implementation Identified. Available from: http://www. ncbi.nlm.nih.gov/pmc/articles/PMC2243512/pdf/procamiasymp000020283.pdf. Accessed July 13, 2017.
8. Emmons KM, Puleo E, Sprunck-Harrild K, et al. Partnership for health-2, a web-based versus print smoking cessation intervention for childhood and young adult cancer survivors: randomized comparative effectiveness study. J Med Internet Res. 2013;15(11):e218.

9. Yardley L, Kirby S. Evaluation of booklet-based self-management of symptoms in Meniere disease: a randomized controlled trial. Psychosom Med. 2006;68(5):762-769.

10. Thorén E, Sevensson M, Törnqvist A, Andersson G, Carlbring P, Lunner T. Rehabilitative online education versus Internet discussion group for hearing aid users: a randomized controlled trial. $J$ Am AcadAudiol. 2011;22:274-285.

11. Beukes E, Baguley DM, Allen PM, Manchaiah V, Andersson G. Guided Internet-based cognitive behaviour therapy for adults with tinnitus in the United Kingdom: a randomised controlled trial. Ear Hear. 2017. In press.

12. Rasku J, Pyykkö I, Levo H, Kentala E, Manchaiah V. Disease profiling for computerized peer-support of Ménière's disease. JMIR Rehabil Assist Technol. 2015;2(2):e9.

13. Pyykkö I, Manchaiah V, Levo H, Kentala E, Juhola M. Internet-based peer support for Ménière's disease: a summary of web-based data collection, impact evaluation, and user evaluation. Int J Audiol. 2017; 55(7):453-463.

14. Pyykkö I, Manchaiah V, Levo H, Kentala E, Juhola M. Internet-based peer support for Ménière's disease: details and outcome of a webbased peer support program in a single group open trial. Am J Audiol. In Press 2017.

15. Finlex Data Bank. Medical research act. 2017. Available from: http:// www.finlex.fi/en/laki/kaannokset/1999/en19990488.pdf. Accessed July 10, 2017.

16. Graneheim UH, Lundman B. Qualitative content analysis in nursing research: concepts, procedures and measures to achieve trustworthiness. Nurse Educ Today. 2004;24(2):105-112.

17. World Health Organization. Innovative Care for Chronic Conditions: Building Blocks for Action. Geneva: World Health Organization; 2002.

18. Fisher EB, Ayala GX, Ibarra L, et al; Peers for Progress Investigator Group. Contributions of peer support to health, health care, and prevention: papers from peers for progress. Ann Fam Med. 2015;13(1):S2-S8.

19. Lauckner HM, Hutchinson SL. Peer support for people with chronic conditions in rural areas: a scoping review. Rural Remote Health. 2016; 16(1):3601.

20. Blickem C, McPherson K, Hunt K, Gilbody S, Richardson G. The effectiveness of self-management support interventions for men with long-term conditions: a systematic review and meta-analysis. $B M J$ Open. 2015;20;5(3):e006620.

21. Gosling SD, Vazire S, Srivastava S, John OP. Should we trust web-based studies? A comparative analysis of six preconceptions about Internet questionnaires. Am Psychol. 2004;59(2):93-104.

22. Porter M, Boothroyd AR. Symptom severity, social support, coping styles, and quality of life among indviduals' diagnosed with Ménière's disease. Chronic Illn. 2015;11(4):256-266.

23. Ritter P, Lorig K, Laurent D, Matthews K. Internet versus mailed questionnaires: a randomized comparison. $J$ Med Internet Res. 2004; $15 ; 6(3): \mathrm{e} 29$
Patient Preference and Adherence

\section{Publish your work in this journal}

Patient Preference and Adherence is an international, peer-reviewed, open access journal that focuses on the growing importance of patient preference and adherence throughout the therapeutic continuum. Patient satisfaction, acceptability, quality of life, compliance, persistence and their role in developing new therapeutic modalities and compounds to optimize

\section{Dovepress}

clinical outcomes for existing disease states are major areas of interest for the journal. This journal has been accepted for indexing on PubMed Central. The manuscript management system is completely online and includes a very quick and fair peer-review system, which is all easy to use. Visit http://www. dovepress.com/testimonials.php to read real quotes from published authors. 